\title{
ASP2397: a novel antifungal agent produced by Acremonium persicinum MF-347833
}

\author{
Ikuko Nakamura, Seiji Yoshimura, Teruhisa Masaki, Shigehiro Takase, Keisuke Ohsumi, Michizane Hashimoto, \\ Shigetada Furukawa and Akihiko Fujie
}

The novel antifungal agent ASP2397 (Vical's compound ID VL-2397) is produced by the fungal strain MF-347833 that was isolated from Malaysian leaf litter and is identified here as an Acremonium species based on its morphology, physiological properties and $28 \mathrm{~S}$ ribosomal DNA sequence. Because of its potential importance for producing novel antifungal agents, we determined the taxonomic and biologic properties of MF-347833. We show here that ASP2397 is a cyclic hexapeptide that chelates aluminum ion and is therefore similar to ferrichrome, a hydroxamate siderophore. However, ASP2397 differs structurally from licensed antifungal agents such as amphotericin B, triazoles and echinocandins. To understand the relationship between chemical structure and biological function, we isolated certain ASP2397 derivatives from the culture broth, and we further chemically converted the metal-free form to other derivatives.

The Journal of Antibiotics (2017) 70, 45-51; doi:10.1038/ja.2016.107; published online 7 September 2016

\section{INTRODUCTION}

Invasive pulmonary aspergillosis is a major direct or contributory cause of mortality for immunocompromised patients. ${ }^{1}$ Our efforts to discover new fungicidal agents for treating invasive pulmonary aspergillosis included collecting microorganisms from tropical forests to increase the geographic diversity of our sources, developing a rationally designed library of drug candidates and implementing a rapid in vivo screening system. ${ }^{2}$ The culmination of this research was the isolation of the novel antifungal agent ASP2397 from an Acremonium species designated MF-347833 (Figure 1).

The structure of ASP2397 differs from those of licensed antifungal agents such as amphotericin B, triazoles (fluconazole, itraconazole, voriconazole, posaconazole and isavuconazole) and echinocandins (caspofungin, micafungin and anidulafungin). ASP2397 is a structural relative of ferrichrome, a low-molecular-weight siderophore. Siderophores are produced by bacteria, fungi and plants in response to iron depletion. ${ }^{3,4}$

Understanding the relationship between the structure and function of a drug is extremely important for determining its mode of action. Therefore, to exploit our discovery of ASP2397 to develop drugs with even greater efficacy and safety for treating patients with invasive pulmonary aspergillosis, we isolated the ASP2397 derivatives AS2488053, AS2488059, AS2524371 and AS2529132. Furthermore, we determined the taxonomy of the ASP2397-producing Acremonium strain, the culture methods required for the production of ASP2397 as well as the physicochemical properties, structure and biological properties of ASP2397 and its derivatives.

\section{RESULTS}

Taxonomic classification of strain MF-347833

Colonies of strain MF-347833 were $39-41 \mathrm{~mm}$ in diameter when grown on potato dextrose agar (PDA) at $25^{\circ} \mathrm{C}$ for 2 weeks, and conidia were observed within the first week. The surfaces of the colonies were floccose with undulate margins. Each colony exhibited sulcates that radiated from the center to the margin; however, these sulcate striates were difficult to observe from the surface. The colonies were white (1A1) and yellowish white (4A2) at the center. The sulcates that radiated from the center to the margin were identified from the reverse orientation. The colonies were generally ivory (4A3) and mustard brown (5E6) at the center. After 2 weeks, the colonies grew to a diameter of $\sim 24 \mathrm{~mm}$ at $30^{\circ} \mathrm{C}$, and no growth was observed at 5 or $37^{\circ} \mathrm{C}$. The colonies grew on cornmeal agar to a diameter of $39-40 \mathrm{~mm}$ at $25^{\circ} \mathrm{C}$ in 2 weeks. The surface of each colony was felty, the margin was undulate, the colonies were not sulcate and the surface and interior of each were white (1A1). In 2 weeks, the colonies attained a diameter of $14 \mathrm{~mm}$ at $30^{\circ} \mathrm{C}$ and were not sulcate. No growth was observed at 5 and $37^{\circ} \mathrm{C}$.

The morphological characteristics described here refer to growth on PDA. Vegetative hyphae ranged in width from 1.8 to $2.7 \mu \mathrm{m}$, and chlamydospores were absent. Conidiophores were hyaline, unbranched and arose singly from a single vegetative hypha or from plectonematogenous hyphae. Numerous warts were observed on the conidiophore, and the base was septate. Conidial ontogeny was phialidic, and the length from the base of each conidiophore to the apex of the phialide was $33-40 \mu \mathrm{m}$. Conidia were hyaline and ellipsoidal. Diameters ranged $3.7 \times 4.5 \times 2.8-3.2 \mu \mathrm{m}$ (average, $4 \times 3 \mu \mathrm{m})$, and aggregated in a mass at the apex of a phialide but

Drug Discovery Research, Astellas Pharma Inc., Ibaraki, Japan

Correspondence: I Nakamura, Drug Discovery Research, Astellas Pharma Inc., 21 Miyukigaoka, Tsukuba, Ibaraki 305-8585 Japan.

E-mail: ikuko.nakamura@astellas.com

Received 6 May 2016; revised 21 July 2016; accepted 1 August 2016; published online 7 September 2016 


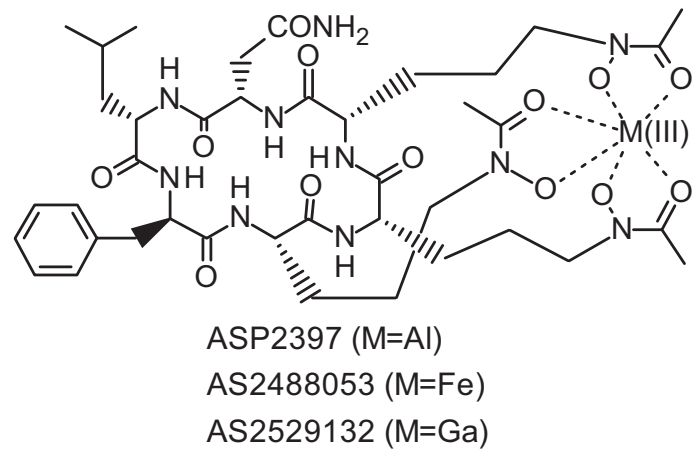

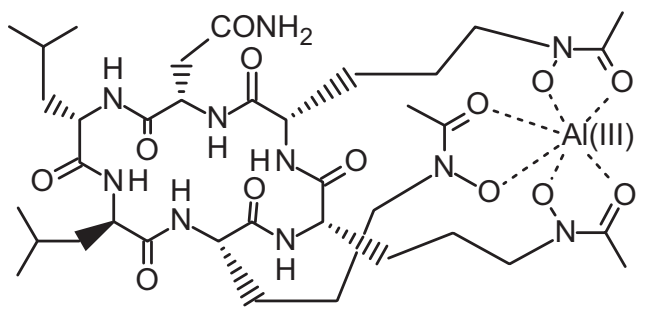

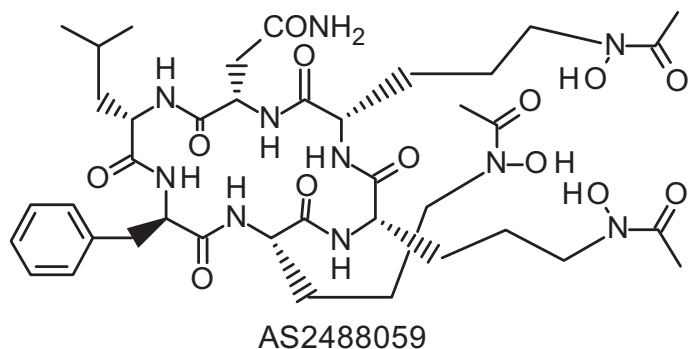

AS2524371

Figure 1 Structure of ASP2397, AS2488053, AS2488059, AS2524371 and AS2529132.

a

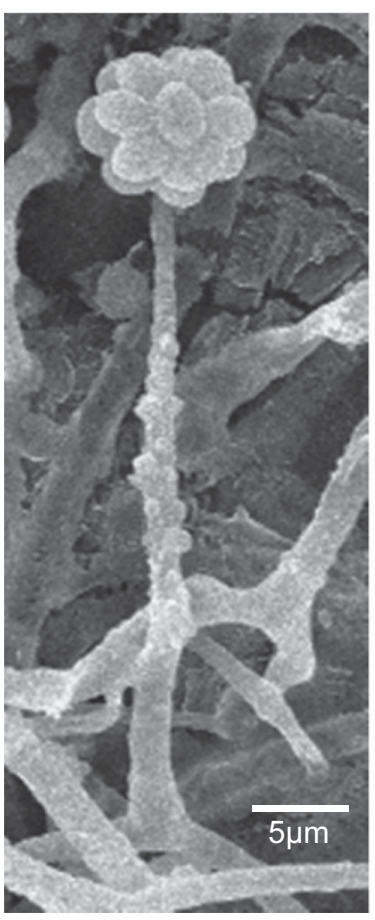

b

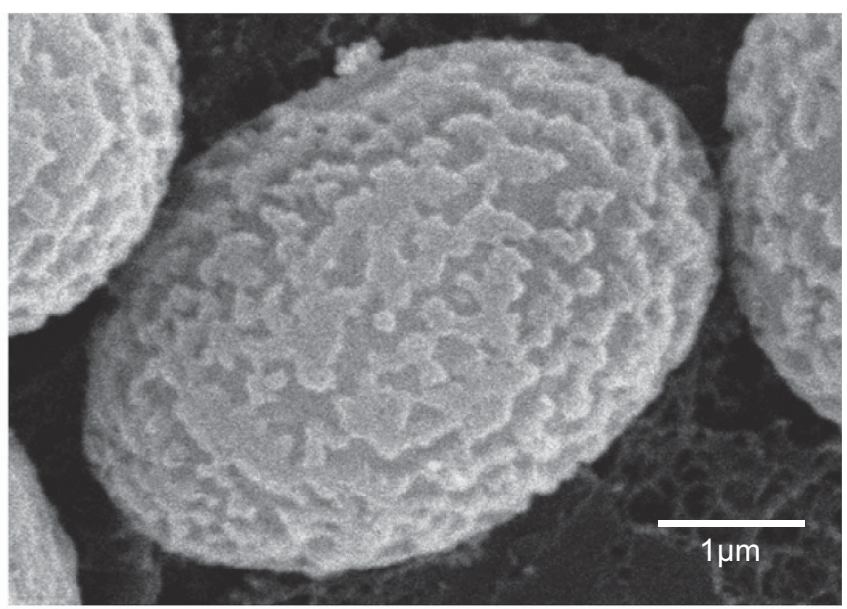

Figure 2 Morphological characteristics of MF-347833 (scanning electron microscopy). (a) Conidiophore and (b) Conidia.

never in a chain (Figure 2a). Light microscopy $(\times 400)$ revealed a smooth surface that appeared as roughly concavo-convex pattern (×9000) when observed using a scanning electron microscope (Figure 2b).

These morphological characteristics are indicative of the genus Acremonium. The morphological characteristics of the strain were consistent with those of Acremonium persicinum. ${ }^{5}$ Furthermore, comparisons of the sequences of $28 \mathrm{~S}$ ribosomal DNA identified strain MF-347833 as a member of the A. persicinum clade (Figure 3). Therefore, we identified MF-347833 as A. persicinum and designated the strain as A. persicinum, MF-347833. 


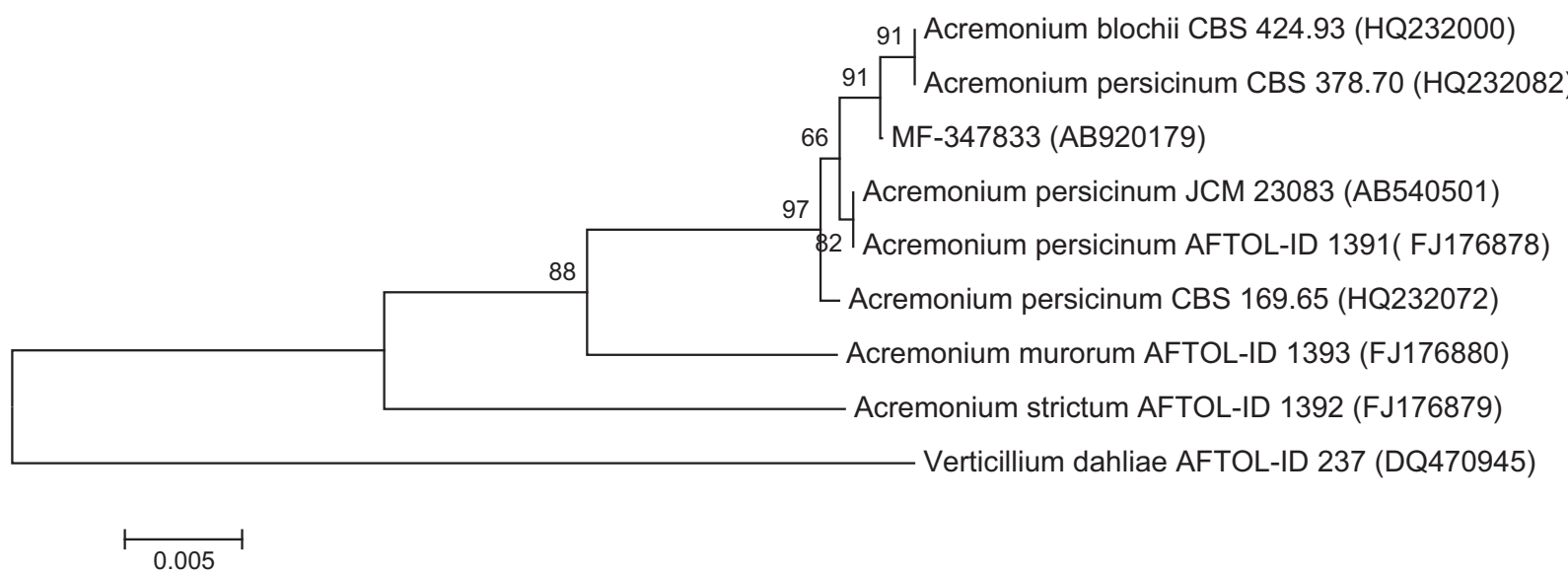

Figure 3 Phylogenic tree of MF-347833 and related species generated according to 28S ribosomal DNA sequences. Verticillium dahliae (AFTOL-ID237) served as an outlier.

Isolation and purification

ASP2397 and AS2524371. ASP2397 and AS2524371 were isolated from a 20-1 broth culture of Acremonium sp. MF-347833 using the procedure as follows: an equal volume of acetone was added to the culture broth and filtered to obtain the culture extract that was diluted with an equal volume of water and applied to a Diaion SP 850 column (5 1, Mitsubishi Chemical Corporation, Tokyo, Japan). The column was eluted with $40 \%$ acetone, and the eluate $(32.5 \mathrm{l})$ was diluted with two volumes of water and applied to a Daisogel SP-120-ODS-B column $(15 / 30 \mu \mathrm{m}, 8$ l; OSAKA SODA Co., LTD, Osaka, Japan) and eluted with $30 \% \mathrm{CH}_{3} \mathrm{CN}$. The eluate of $4 \mathrm{l}$ (the latter half of $8.8 \mathrm{l}$ ) was then diluted with an equal volume of water and applied to a Daisogel SP-120-ODS-B column (1 1 OSAKA SODA Co., Ltd) and eluted with $\mathrm{MeOH}$ and acetone. The eluate was concentrated under reduced pressure, lyophilized and crystallized using $\mathrm{MeOH}$, ethyl acetate and $N$-hexane to obtain ASP2397 (16.3 g). The eluate of 41 (the first half of $8.8 \mathrm{l}$ ) was then diluted with an equal volume of water and applied to a Daisogel SP-120-ODS-B column $(180 \mathrm{ml})$ and eluted with $25 \%$ $\mathrm{CH}_{3} \mathrm{CN}$. The eluate was purified using preparative HPLC (Mightysil RP-18 GP250 $\times 20$ column, $5 \mu \mathrm{m}$; Kanto Chemical, Tokyo, Japan). The column was eluted $\left(10 \mathrm{ml} \mathrm{min}^{-1}\right)$ with $30 \% \mathrm{CH}_{3} \mathrm{CN}$. The eluate containing AS2524371 was collected and dried to obtain AS2524371 (6.0 mg).

AS2488059. AS2488059 was isolated from 2.61 of culture broth of Acremonium sp. MF-347833 using the procedure as follows: an equal volume of acetone was added to the culture broth that was then filtered to obtain the culture extract. The filtrate was diluted twofold with water and applied to a Diaion SP 850 column (400 ml; Mitsubishi Chemical Corporation) that was eluted with $30 \%$ acetone. The eluate (1.91) was diluted with water (2.11) water, applied to a Daisogel SP-120-ODS-B column (15/30 $\mu \mathrm{m}$; size, $350 \mathrm{ml}$; DAISO) and eluted with $25 \% \mathrm{CH}_{3} \mathrm{CN}(340 \mathrm{ml})$. The eluate was diluted with an equal volume of water and applied to an OASIS HLB cartridge $(6 \mathrm{~g}$, Waters, Tokyo, Japan), and eluted with $\mathrm{MeOH}(150 \mathrm{ml})$. The eluate was concentrated under reduced pressure, and acetone was added to the concentrate to obtain a precipitate that was dried to a yellow powder $(100 \mathrm{mg})$. A small volume of $\mathrm{MeOH}$ was used to dissolve $15 \mathrm{mg}$ of the precipitate, and the solution was loaded onto a preparative HPLC (Symmetry $7-\mu \mathrm{m}$ C18 column, $19 \times 300 \mathrm{~mm}$; Waters) and eluted at $7 \mathrm{ml} \mathrm{min}{ }^{-1}$ with $27 \% \mathrm{CH}_{3} \mathrm{CN}$ containing $0.05 \%$ TFA. The peak that eluted at $\sim 22 \mathrm{~min}$ was collected, mixed with an equal volume of water and applied to an OASIS HLB cartridge (size: $500 \mathrm{mg}$ ). Water $(50 \mathrm{ml})$ was passed through the cartridge that was then eluted using $\mathrm{MeOH}$ $(50 \mathrm{ml})$. This eluate was concentrated under reduced pressure, and acetone was added to the concentrate to obtain a precipitate that was dried to yield a white powder (13 mg).

\section{Preparation of AS2488053 and AS2529132}

AS2488059 (2 mg) was dissolved in $\mathrm{MeOH}(0.2 \mathrm{ml})$ and water $(0.2 \mathrm{ml})$, mixed with an aqueous solution $(0.6 \mathrm{ml})$ of $\mathrm{FeCl}_{3} \cdot 6 \mathrm{H}_{2} \mathrm{O}$ $(5 \mathrm{mg})$ and stirred for $2.25 \mathrm{~h}$ at room temperature. Water was added, and the solution was applied to an OASIS HLB cartridge $(30 \mathrm{mg}$, Waters). Water $(3 \mathrm{ml})$ was passed through the cartridge, and the desired compound was eluted from the cartridge with $\mathrm{MeOH}(2 \mathrm{ml})$. The resulting eluate was concentrated under reduced pressure and dried to obtain AS2488053 as an orange powder (4 mg). Similarly, AS2529132 was obtained from AS2488059 and $\mathrm{Ga}_{2}\left(\mathrm{SO}_{4}\right)_{3} \cdot \mathrm{nH}_{2} \mathrm{O}$ as a white powder.

\section{Analysis of physicochemical properties and determination of} structures

The physicochemical properties of ASP2397, AS2488053, AS2488059, AS2524371 and AS2529132 are summarized in Table 1. The molecular mass of ASP2397 determined using HR-ESI-MS was 915.4191 $\mathrm{Da}\left([\mathrm{M}+\mathrm{H}]^{+}\right)$that corresponds to the formula $\mathrm{C}_{40} \mathrm{H}_{59} \mathrm{AlN}_{10} \mathrm{O}_{13}$ (theoretical, $[\mathrm{M}+\mathrm{H}]^{+}=915.4157 \mathrm{Da}$ ) determined using HR-ESI-MS and the NMR data. The presence of aluminum was supported by the results of energy-dispersive X-ray spectroscopy. The ${ }^{13} \mathrm{C}$-NMR signals from all 40 carbons were detected, including carbons from 10 carbonyls, a benzene (4 signals due to symmetry), 12 methylenes, 7 methines and 5 methyls. Among the 10 carbonyls, 3 that resonated at $161.6,161.7$, and $161.3 \mathrm{ppm}$ were assigned as acetyl groups using heteronuclear multiple bond correlation (HMBC) correlations with the singlet methyl protons at $2.11,2.09$ and $2.04 \mathrm{ppm}$, respectively. HMBC was used to assign the carbonyl signal at $173.8 \mathrm{ppm}$ as a carbamoyl group with two exchangeable protons at 7.76 and 7.39 ppm, and the remaining carbonyls were assigned as amide groups (vide infra), indicating that ASP2397 is a hexapeptide. Assuming that the $\mathrm{Al}$ ion in ASP2397 is trivalent, the degree of unsaturation of ASP2397 would be 17, according to the molecular formula. This degree of unsaturation can be partly explained by the presence of 4 benzenyls and 10 carbonyls. Thus, the remaining degree of unsaturation indicates that ASP2397 is tricyclic. 
Table 1 Physicochemical properties of ASP2397, AS2488053, AS2488059, AS2524371 and AS2529132

\begin{tabular}{|c|c|c|c|c|c|}
\hline & ASP2397 & AS2488053 & AS2488059 & AS2524371 & AS2529132 \\
\hline Appearance & Colorless crystals & Orange crystals & White powder & White powder & White powder \\
\hline Optical rotation & 160.28 & 362.00 & -42.96 & 277.50 & 324.16 \\
\hline$[\alpha]_{D}\left(22^{\circ} \mathrm{C}, \mathrm{MeOH}\right)$ & (c 0.012) & (c 0.01 ) & (c 0.01 ) & (c 0.012) & (c 0.012) \\
\hline Molecular formula & $\mathrm{C}_{40} \mathrm{H}_{59} \mathrm{AlN}_{10} \mathrm{O}_{13}$ & $\mathrm{C}_{40} \mathrm{H}_{59} \mathrm{FeN}_{10} \mathrm{O}_{13}$ & $\mathrm{C}_{40} \mathrm{H}_{62} \mathrm{~N}_{10} \mathrm{O}_{13}$ & $\mathrm{C}_{37} \mathrm{H}_{61} \mathrm{AlN}_{10} \mathrm{O}_{13}$ & $\mathrm{C}_{40} \mathrm{H}_{59} \mathrm{GaN}_{10} \mathrm{O}_{13}$ \\
\hline \multicolumn{6}{|l|}{ HR ESI-MS } \\
\hline Found $(\mathrm{M}+\mathrm{H})^{+}$ & 915.4191 & 944.3693 & 891.4592 & 881.4304 & 957.3597 \\
\hline Calculated $(\mathrm{M}+\mathrm{H})^{+}$ & 915.4157 & 944.3691 & 891.4576 & 881.4313 & 957.3597 \\
\hline $\mathrm{IR}(\mathrm{KBr}) \mathrm{cm}^{-1}$ & $\begin{array}{c}3300,2930,1680,1650,1620 \\
1520,1370,1240,1140,990\end{array}$ & NT & $\begin{array}{c}3300,2950,1680,1650,1640 \\
1540,1460,1420,1240,1210 \\
1160,1040,970\end{array}$ & NT & NT \\
\hline $\begin{array}{l}\text { HPLC retention } \\
\text { time }(\min )^{a}\end{array}$ & $8.7^{b}$ & $10.4^{b}$ & $4.2^{\mathrm{b}}$ & $5.4^{c}$ & $13.5^{\mathrm{b}}$ \\
\hline TLC (Rf value) $)^{d}$ & 0.5 & 0.5 & 0.25 & NT & NT \\
\hline \multicolumn{6}{|l|}{ Color test } \\
\hline Positive & $\begin{array}{c}\mathrm{I}_{2}, \mathrm{Ce}\left(\mathrm{SO}_{4}\right)_{2}-\mathrm{H}_{2} \mathrm{SO}_{4}, \text { Ehrlich, } \\
\text { Dragendorf }\end{array}$ & $\begin{array}{l}\mathrm{I}_{2}, \mathrm{Ce}\left(\mathrm{SO}_{4}\right)_{2}-\mathrm{H}_{2} \mathrm{SO}_{4} \\
\text { Ehrlich, Dragendorf }\end{array}$ & $\begin{array}{c}\mathrm{I}_{2}, \mathrm{Ce}\left(\mathrm{SO}_{4}\right)_{2}-\mathrm{H}_{2} \mathrm{SO}_{4}, \text { Ehrlich, } \\
\text { Dragendorf, } \mathrm{FeCl}_{3}\end{array}$ & NT & NT \\
\hline Negative & Molish, Ninhydrin, $\mathrm{FeCl}_{3}$ & Molish, Ninhydrin, $\mathrm{FeCl}_{3}$ & Molish, Ninhydrin & NT & NT \\
\hline \multicolumn{6}{|l|}{ Solubility } \\
\hline Soluble & methanol, DMF, DMSO & methanol, DMF, DMSO & methanol, DMSO & methanol, DMSO & NT \\
\hline Insoluble & ethyl acetate, n-hexane & ethyl acetate, n-hexane & NT & NT & NT \\
\hline $\begin{array}{l}\text { Amino-acid } \\
\text { analysis }\end{array}$ & L-Asn, L-Leu, D-Phe & NT & NT & L-Asn, L-Leu, D-Leu & NT \\
\hline
\end{tabular}

Abbreviation: NT, not tested.

aRetention times (Mightysil RP-18 GP 150-4.6 $5 \mu \mathrm{m}$ Kanto Chemical, $1 \mathrm{ml} \mathrm{min}{ }^{-1}$ ).

b28\% Aqueous $\mathrm{CH}_{3} \mathrm{CN}$ containing $0.5 \% \mathrm{NH}_{4} \mathrm{H}_{2} \mathrm{PO}_{4}$.

c30\% Aqueous $\mathrm{CH}_{3} \mathrm{CN}$ containing $0.5 \% \mathrm{NH}_{4} \mathrm{H}_{2} \mathrm{PO}_{4}$.

dSilica gel 60 F254 (MERCK): methanol/chroloform (1:5).

Total correlation spectroscopy (spin-lock, $120 \mathrm{~ms}$ ), and heteronuclear single quantum correlation identified the amino acid residues as asparagine, leucine, phenylalanine and three ornithines. The presence of the acetyl amide of each ornithine residue was deduced according to $\mathrm{HMBC}$ correlations between the corresponding carbonyl carbon (161.6, 161.7 and $161.3 \mathrm{ppm})$ and the methylene proton (3.36, 3.67 and $3.70 \mathrm{ppm})$, respectively. The peptide sequence was determined using HMBC. The data supporting the conclusion that ASP2397 is a cyclic hexapeptide are shown in Figure 4.

However, these data did not account for an $\mathrm{Al}$ bond and three oxygen atoms. Because each nitrogen atom of the ornithine side chains would form a bond with one of the unassigned atoms, the most reasonable structure would include three hydroxamic acids complexed with $\mathrm{Al}$, similar to the structure of ferrichrome. We therefore performed single-crystal X-ray crystallography. A needle-shaped single crystal was obtained from the $\mathrm{MeOH}$ solution, and the Oak Ridge thermal ellipsoid plot (Figure 5) allowed determination of the complete structure of ASP2397 (Figure 1). The molecular formula $\left(\mathrm{C}_{40} \mathrm{H}_{62} \mathrm{~N}_{10} \mathrm{O}_{13}\right)$ determined using HR-ESI-MS indicated that AS2488059 is the siderophore core of ASP2397. ${ }^{1} \mathrm{H}-\mathrm{NMR}$ analysis detected three exchangeable protons around $9.7 \mathrm{ppm}$ (not shown in Table 2) that we assigned as the hydroxamic acid protons. Furthermore, the planar structure of ASP2488059 was identified as the corresponding free ligand (Table 2).

Because AS2488059 was converted to ASP2397 by treatment with $\mathrm{AlK}\left(\mathrm{SO}_{4}\right)_{2} \cdot 12 \mathrm{H}_{2} \mathrm{O}$, we concluded that the stereochemistry of AS2488059 was identical to that of ASP2397. The HR-ESI-MS data

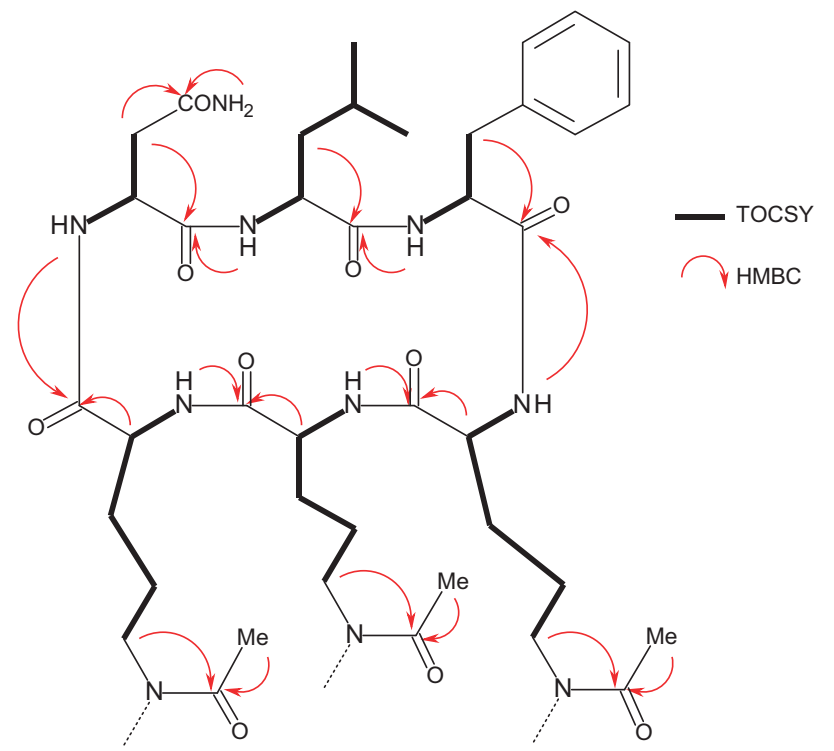

Figure 4 Summary of NMR analysis of ASP2397.

allowed us to assign the molecular formula $\mathrm{C}_{37} \mathrm{H}_{61} \mathrm{AlN}_{10} \mathrm{O}_{13}$ to AS2524371. Modified Marfey's analysis revealed the presence of D-Leu instead of D-Phe. The identities and sequence of the amino acid residues were confirmed using NMR analysis as described for 


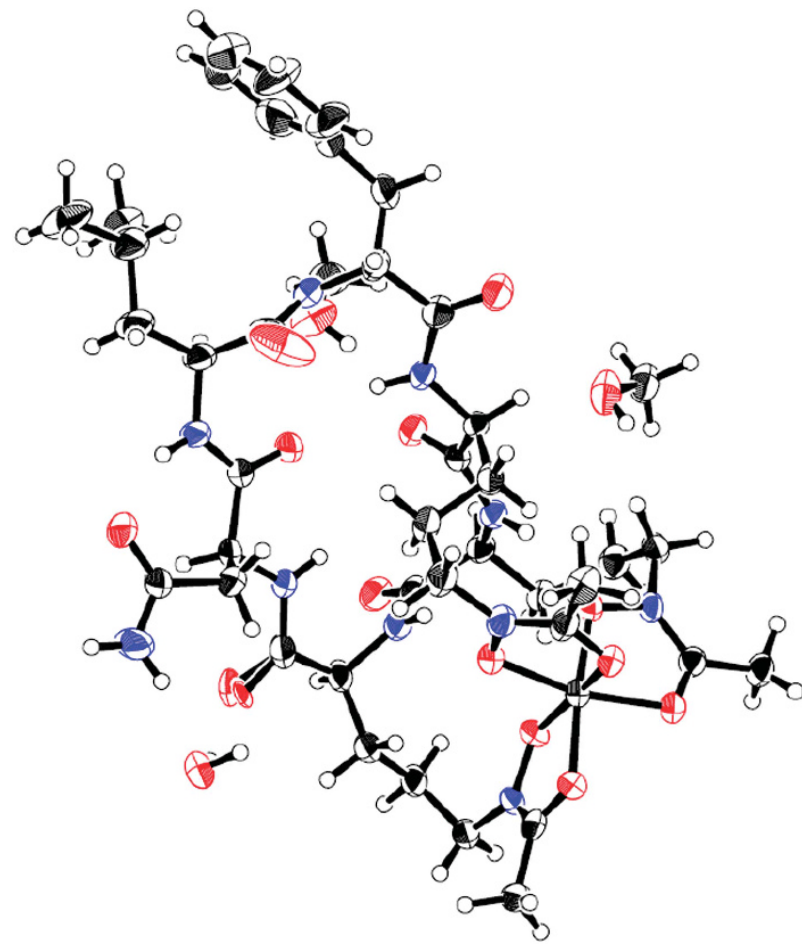

Figure 5 Oak Ridge thermal ellipsoid plot of ASP2397. Water-oxygen occupancy was $\sim 50 \%$ that accounts for the disordered oxygen close to the water molecule. The space group was found to be P212121. The final refinement gave R1 of 0.0617 and a Flack parameter of 0.02 (9).

ASP2397, and the NMR assignments of AS2524371 and chemically synthesized AS2529132 are shown in Table 2.

The molecular formula $\left(\mathrm{C}_{40} \mathrm{H}_{59} \mathrm{FeN}_{10} \mathrm{O}_{13}\right)$ determined using HR-ESI-MS supported that AS2488053 is the replaced body of $\mathrm{Al}$ in ASP2397 by Fe. As expected, NMR signals of AS2488053 were very broad because of its ferromagnetic property, supporting the existence of Fe. However, this ferromagnetism precluded further structural analysis by NMR. Efforts to obtain a single crystal turned out to be in vain.

\section{Biological activity}

The inhibitory activities of ASP2397 and its derivatives of the growth of Aspergillus fumigatus are shown in Table 3. ASP2397 and AS2529132 were fungicidal when added to RPMI medium and in a medium containing mouse serum $\left(0.20-0.78 \mu \mathrm{g} \mathrm{ml}^{-1}\right)$. In contrast, AS2488053 was less inhibitory in both media and was fungistatic $\left(\mathrm{MIC}>50 \mu \mathrm{g} \mathrm{ml}^{-1}\right.$, minimum effective concentration $=0.39 \mu \mathrm{g} \mathrm{ml}^{-1}$ in RPMI medium). AS2488059 was inhibitory in RPMI medium $\left(\mathrm{MIC}=0.78 \mu \mathrm{g} \mathrm{ml}^{-1}\right)$ but not in the presence of mouse serum. These four compounds have the same scaffold structure, except for their chelating metal ion. AS2524371, which differs by one amino acid residue from ASP2397 and binds $\mathrm{Al}$ ion as well, was not detectably antifungal in RPMI medium.

\section{DISCUSSION}

We describe here the isolation and characterization of the novel antifungal agent ASP2397 that was isolated from the fermentation broth of a fungal isolate designated MF-347833 that we identified as A. persicinum according to its morphology and $28 \mathrm{~S} \mathrm{rDNA}$ sequence. Furthermore, we isolated naturally occurring and synthetic derivatives of ASP2397 and evaluated their ability to inhibit the growth of A. fumigatus,

We speculate that MF-347833 originally produced only the metalfree form, such as AS2488059, that is equivalent to the Al-free form of ASP2397, because the addition of $\mathrm{Al}$ ion to the culture medium increased the yield of ASP2397. These findings indicate that AS2488059 chelates Al or other metal ions present in the culture medium.

Microorganisms require iron for survival and can use siderophore to acquire iron from the environment. The structure of ASP2397 is similar to that of ferrichrome, ${ }^{3}$ a siderophore with high specificity for iron. We prepared alumichrome ${ }^{6}$ that, in the presence of deferriferrichrome, chelates the $\mathrm{Al}$ ion; however, neither compound inhibited the growth of A. fumigatus (data not shown). Therefore, we assume that $\mathrm{Al}$ ion is not required for antifungal activity. Furthermore, we suggest that AS2488059 chelated free Al or ferrous ion in the RPMI culture medium during tests of its antifungal activity, indicating that the antifungal activity of AS2488059 requires a chelated metal ion. In contrast, a serum-containing medium may not include sufficient free $\mathrm{Al}$ ion to bind to AS2488059 that likely accounts for its lack of antifungal activity in serum-containing medium. We previously reported that the MIC determined in serum-containing medium correlates accurately with the preclinical in vivo effects of antifungals. ${ }^{7}$ Among the ASP2397 derivatives studied here, only ASP2397 and AS2529132 produced by MF-347833 were active in serum-containing medium. In contrast, AS2488053 was not active in serum-containing medium and did not increase the survival rate in mice with disseminated aspergillosis caused by A. fumigatus. ${ }^{2}$

Because ASP2397 is a potent inhibitor of Aspergillus species that is more soluble than AS2529132, it was selected as a candidate for evaluation of in vitro and in vivo activities. We found that ASP2397 was not cytotoxic for mammalian cells at concentrations as high as $50 \mu \mathrm{g} \mathrm{ml}^{-1}$ (data not shown), indicating its potential as a therapeutic drug; however, further studies are required to determine the antifungal mechanisms of ASP2397 and its derivatives.

\section{MATERIALS AND METHODS}

\section{Phylogenetic analysis}

The fungal strain MF-347833 was isolated from leaf litter collected at Endau Rompin National Park (Johor, Malaysia). This strain (FERM BP-10916; 10 October 2007) was contributed to the collection of the International Patent Organism Depository, National Institute of Advanced Industrial Science and Technology, and its DNA sequence data were submitted to the DNA Data Bank of Japan under accession number AB920179 (25 March 2014). The analysis of DNA sequences and the generation of a phylogenetic tree were performed using MEGA ver. 5.2. ${ }^{8}$ The strain was incubated on PDA (213200, Becton Dickinson, Tokyo, Japan) at $25^{\circ} \mathrm{C}$ in the dark to observe colony formation. The cells were observed using a light microscope (Leica DM2500, Leica Microsystems, Tokyo, Japan) and a scanning electron microscope (Hitachi S-2600N, Hitachi HighTechnologies, Tokyo, Japan). Colors of the fungi were determined according to the Methuen Handbook of Colour. ${ }^{9}$

\section{Fermentation}

ASP2397 and ASP2524371. A loopful of a slant culture of MF-347833 was used to inoculate $30 \mathrm{ml}$ of sterilized culture of seed medium (cornstarch $2 \%$, glycerol $1 \%$, sucrose $1 \%$, pharma media $1 \%$, gluten meal $1 \%$ and Tween 80 $0.2 \%$ ) and cultured at $25^{\circ} \mathrm{C}$ for 4 days with shaking on a rotary shaker (220 r.p.m.). The seed culture $(3.2 \mathrm{ml})$ was aseptically inoculated into $160 \mathrm{ml}$ of the same sterilized seed medium in each of three 500-ml Erlenmeyer flasks and was then cultured at $25^{\circ} \mathrm{C}$ for 3 days with shaking on a rotary shaker (220 r.p.m.). These cultures $(480 \mathrm{ml})$ were aseptically inoculated into a $30-1$ jar fermentor containing 201 of sterile production medium (glycerol 5\%, soluble starch (Nacalai Tesque, Kyoto, Japan) 7\%, yeast extract (Wako Pure Chemical 
Table 2 NMR assignments for ASP2397, AS2488059, AS2524371 and AS2529132 in DMSO-d6

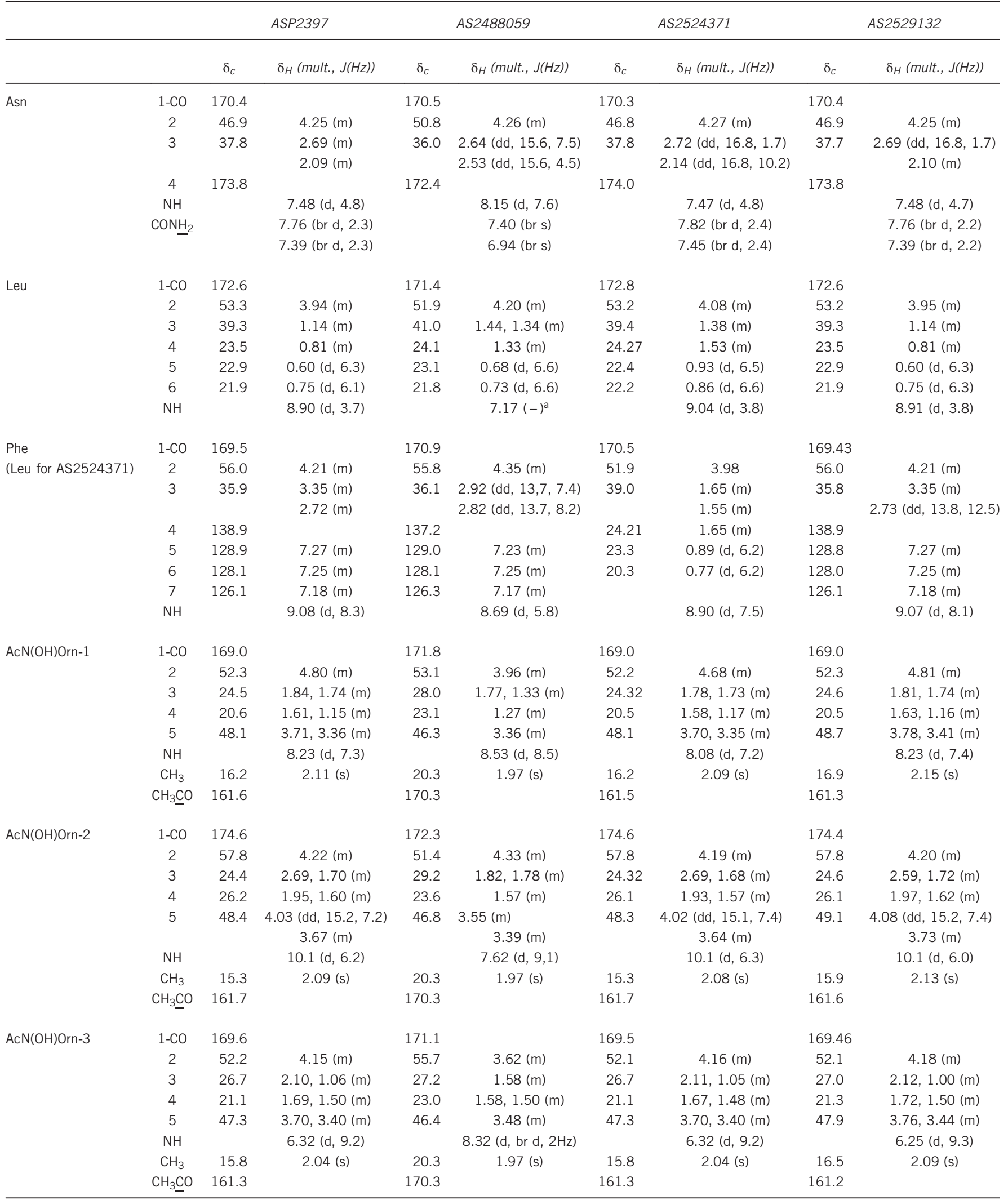

aThis coupling pattern could not be analyzed because of signal overlap. 
Table 3 Relationship between chemical structures and in vitro antifungal activities of ASP2397 and its derivatives

\begin{tabular}{|c|c|c|c|c|c|c|c|c|}
\hline \multirow[b]{2}{*}{ Test substrates } & \multirow[b]{2}{*}{1} & \multirow[b]{2}{*}{2} & \multirow[b]{2}{*}{3} & \multirow[b]{2}{*}{ Metal } & \multicolumn{2}{|c|}{$\operatorname{MIC}\left(\mu g \mathrm{ml}^{-1}\right)$} & \multicolumn{2}{|c|}{$M E C\left(\mu g m l^{-1}\right)$} \\
\hline & & & & & $R P M I$ & $50 \%$ Mice serum & $R P M I$ & $50 \%$ Mice serum \\
\hline ASP2397 & L-Asn & L-Leu & D-Phe & $\mathrm{Al}$ & 0.78 & 0.39 & 0.39 & 0.2 \\
\hline AS2488053 & L-Asn & L-Leu & D-Phe & $\mathrm{Fe}$ & $>50$ & 25 & 0.39 & 12.5 \\
\hline AS2488059 & L-Asn & L-Leu & D-Phe & None & 0.78 & $>50$ & 0.2 & 50 \\
\hline AS2524371 & L-Asn & L-Leu & D-Leu & $\mathrm{Al}$ & $>50$ & NT & $>50$ & NT \\
\hline AS2529132 & L-Asn & L-Leu & D-Phe & $\mathrm{Ga}$ & 0.78 & 0.2 & 0.2 & 0.2 \\
\hline
\end{tabular}

Abbreviations: MEC, minimum effective concentration; NT, not tested.

Aspergillus fumigatus FP1305 served as the target organism.

Industries, Osaka, Japan) $1.5 \%, \beta$-cyclodextrin $1 \%, \mathrm{KNO}_{3} 1 \%$, DL-methionine $1.3 \%, \mathrm{CaCO}_{3} 0.5 \%, \mathrm{AlK}\left(\mathrm{SO}_{4}\right)_{2} \cdot 12 \mathrm{H}_{2} \mathrm{O} 0.3 \%$, Adekanol LG-109 $0.1 \%$ and Silicone KM-70 0.05\%). The culture was incubated at $25^{\circ} \mathrm{C}$ for 6 days with aeration at $201 \mathrm{~min}^{-1}$ and agitation at 200 r.p.m.

AS2488059. The seed culture $(2 \mathrm{ml})$ was used to aseptically inoculate $100 \mathrm{ml}$ of sterilized production medium (glucose $0.5 \%$, soluble starch $1.5 \%$, yeast extract $0.5 \%, \mathrm{KCl} 0.02 \%, \mathrm{MgSO}_{4} \cdot 7 \mathrm{H}_{2} \mathrm{O} 0.02 \%, \mathrm{KH}_{2} \mathrm{PO}_{4} 0.1 \%, \mathrm{NaNO}_{3} 0.2 \%$ ) in $500-\mathrm{ml}$ Erlenmeyer flasks. The culture was incubated at $25^{\circ} \mathrm{C}$ for 7 days with shaking (220 r.p.m.).

\section{HPLC analysis}

Culture fluids were monitored for the presence of ASP2397, AS2488053, AS2488059, AS2524371 and AS2529132 (the latter four described below) using HPLC with a reverse-phase column (Mightysil RP-18 GP 150-4.6, $5 \mu \mathrm{m}$; Kanto Chemical). Aqueous $\mathrm{CH}_{3} \mathrm{CN}\left(28 \%\right.$ or $30 \%$ ) containing $0.5 \% \mathrm{NH}_{4} \mathrm{H}_{2} \mathrm{PO}_{4}$ was used as the mobile phase $\left(1.0 \mathrm{ml} \mathrm{min}^{-1}\right)$, and ASP2397 and its derivatives were detected based on their absorbance at $210 \mathrm{~nm}$.

\section{Spectral analyses}

Spectral analyses of ASP2397 and its derivatives were performed using the instruments as follows: (LC)MS-ion trap (IT)-time-of-flight (TOF) spectrometer (Shimadzu, Kyoto, Japan); UV-2500 PC UV/visible-light spectrophotometer (Shimadzu); SEPA-500 polarimeter (Horiba, Kyoto, Japan); Spectrum 65 FT-IR spectrometer (PerkinElmer Japan Co., Ltd., Yokohama, Japan); and a cryoprobe-equipped Bruker DRX500 or a Bruker Avance II 500 NMR spectrometer.

\section{Amino acid analysis (advanced Marfey's method)}

A sample ${ }^{10}(1 \mathrm{mg})$ was dissolved in aqueous $6 \mathrm{~N} \mathrm{HCl}(0.5 \mathrm{ml})$, heated at $110{ }^{\circ} \mathrm{C}$ for $15 \mathrm{~h}$, and evaporated to dryness; the residue was then dissolved in water $(0.5 \mathrm{ml})$. To $20 \mu \mathrm{l}$ of this solution, acetone solutions of $6 \%$ triethylamine $(10 \mu \mathrm{l})$ and $10 \%$ 1-fluoro-2,4-dinitrophenyl-5- L-valinamide $(20 \mu \mathrm{l})$ were added. The mixture was heated to $40^{\circ} \mathrm{C}$ for $1 \mathrm{~h}$. The reaction was quenched with $0.1 \mathrm{~N} \mathrm{HCl}$ in acetone (50 $\mu \mathrm{l}$ ) and analyzed using an LC/ESI-MS (Shimadzu Liquid Chromatograph Mass Spectrometer System LCMS-2010EV).

\section{Analysis of antimicrobial activity}

The clinical isolate Aspergillus fumigatus FP1305, which was provided by the Teikyo University Institute of Medical Mycology (Tokyo, Japan), was cultured on a PDA slant for 4 days at $37^{\circ} \mathrm{C}$, and the spores were harvested in sterile saline and filtered through gauze. The growth of A. fumigatus was measured using the micro-broth dilution method in 96-well culture plates containing RPMI 1640 medium (Invitrogen Japan, Tokyo, Japan) supplemented with L-glutamine or $50 \%$ mouse serum (Nippon Bio-Supp. Center, Tokyo, Japan) buffered with $0.165 \mathrm{~m}$ MOPS, pH 7.0, respectively. A. fumigatus FP1305 $\left(1 \times 10^{4}\right.$ CFUs per well $)$ was inoculated into each well, and then the plates were incubated for $30 \mathrm{~h}$ at $37^{\circ} \mathrm{C}$. Antifungal activity was determined using a light microscope, and the data are expressed as the minimum effective concentration that showed 50\% reduction of growth compared with the controls, or as the MIC, the lowest concentration that prevented visible growth.

\section{CONFLICT OF INTEREST}

The authors declare no conflict of interest.

\section{ACKNOWLEDGEMENTS}

We thank Dr NB Shahab for collecting natural sources for microorganism isolation in Malaysia (Biotechnology Research Centre, SIRIM Berhad, Selangor, Malaysia) and Dr T Matsumoto (Rigaku Corporation, Tokyo, Japan) for performing single X-ray crystallography.

1 Denning, D. W. Invasive aspergillosis. Clin. Infect. Dis. 26, 781-803, quiz 804-805 (1998).

2 Nakamura, I. et al. Discovery of a new antifungal agent ASP2397 using a silkworm model of Aspergillus fumigatus infection. J. Antibiot. 70, 41-44 (2017).

3 Neilands, J. B. A crystalline organo-iron pigment from a rust fungus (Ustilago sphaerogena). J. Amer. Chem. Soc. 74, 2 (1952).

4 Haas, H., Eisendle, M. \& Turgeon, B. G. Siderophores in fungal physiology and virulence. Annu. Rev. Phytopathol. 46, 149-187 (2008).

5 Gams, W. Cephalosporium-artige Schimmelpilze (Hyphomycetes) 1-262 (Gustav Fischer Verlag, 1971).

6 Llinás, M., Klein, M. P \& Neilands, J. B. Solution conformation of ferrichrome, a microbial iron transport cyclohexapeptide, as deduced by high resolution proton magnetic resonance. J. Mol. Biol. 52, 399-414 (1970).

7 Maki, K. et al. Use of a serum-based antifungal susceptibility assay to predict the in vivo efficacy of novel echinocandin compounds. Microbiol. Immunol. 52, 383-391 (2008).

8 Tamura, K. et al. MEGA5: molecular evolutionary genetics analysis using maximum likelihood, evolutionary distance, and maximum parsimony methods. Mol. Biol. Evol. 28, 2731-2739 (2011).

9 Kornerup, A. \& Wanscher, J. H. Methuen Handbook of Colour. 3rd edn (1987).

10 Fujii, K., Ikai, Y., Oka, H., Suzuki, M. \& Harada, K. A nonempirical method using LC/MS for determination of the absolute configuration of constituent amino acids in peptide: combination of Marfey's Method with mass spectrometry and its practical application. Anal. Chem. 69, 5146-5151 (1997). 